\title{
PRÁTICAS DE EDUCAÇÃO AMBIENTAL: BREVE DIAGNÓSTICO EM ORGANIZAÇÕES MILITARES DO EXÉRCITO BRASILEIRO
}

\section{Practice of environmental education: short diagnosis in military organizations of Brazilian Army}

\author{
Eduardo Borba Neves ${ }^{1}$. Maressa Cristina de Almeida Piconcelli ${ }^{2}$. \\ Sophia Hideko Kohata Oliveira ${ }^{3}$. Brani Rozemberg ${ }^{4}$
}

\begin{abstract}
Resumo: Este trabalho teve por objetivo diagnosticar como a Educação Ambiental (EA) vem sendo desenvolvida no Exército Brasileiro. A abordagem utilizada foi a qualitativa. Foram selecionadas 52 unidades, de forma não probabilística e por conveniência. $\mathrm{O}$ instrumento de coleta de dados foi um questionário com perguntas abertas, enviado às organizações militares no segundo semestre de 2009. A análise dos dados deu-se por meio da análise de conteúdo. Pode-se constatar que as atividades de EA mais mencionadas foram: palestras, instruções ou reuniões; a preocupação com o lixo, rejeitos, reciclagem e uso dos recursos naturais; o plantio de mudas, proteção de áreas verdes e instrução de combate a incêndios. Entretanto, a maioria destas de caráter pontual e descontínuo, o que caracterizou uma EA de enfoque conservacionista. Apenas nos Colégios Militares, observaram-se ações que privilegiavam as ações contínuas e contextualizadas, no sentido de uma EA crítica, transformadora e emancipatória.
\end{abstract}

Palavras-chave: Educação ambiental. Exército Brasileiro. Meio ambiente.

\begin{abstract}
This study aimed to diagnose as the Environmental Education (EE) has been developed in the Brazilian Army. The approach used was qualitative. We selected 52 units, so the sampling was nonprobabilistic and convenience. The data collection instrument was a questionnaire with open questions, which was sent to military organizations, in the second half of 2009. Data analysis was made through content analysis. It may be noted that most EE activities mentioned were: lectures, meetings or instruction; concern about the trash, waste, recycling and use of natural resources, planting seedlings, protection of green areas and instruction of firefighting. However, most of these were infrequent and discontinuous, which featured an EE approach to conservation. Only in Military Schools, were there programs that favored continuous action and contextualized the sense of EE as critical, transformative and emancipator.
\end{abstract}

Keywords: Environmental education. Brazilian Army. Environment.

\footnotetext{
${ }^{1}$ Programa de Pós-Graduação em Engenharia Biomédica, Universidade Tecnológica Federal do Paraná (UTFPR). Av. Sete de Setembro, 3165, Rebouças. Curitiba, PR, Brasil. 80.230-901. borbaneves@hotmail.com

${ }^{2,3}$ Pós-Graduandos em Gestão Ambiental, Faculdades São José. Rio de Janeiro, RJ, Brasil.

${ }^{4}$ Programa de Pós-Graduação em Saúde Pública, Escola Nacional de Saúde Pública. Rio de Janeiro, RJ, Brasil.
} 
Neves, E. B.

\section{Introdução}

Há alguns séculos, o mundo tem vivido uma crise nas relações entre as sociedades e meio ambiente, que se evidencia em situações de conflito, esgotamento e destrutividade (LIMA, 1999). A concepção que tinha o homem e a natureza como polos excludentes, vendo-a apenas como fonte ilimitada de matéria-prima, foi a base para práticas industriais com intensa exploração dos recursos naturais, causando efeitos muito negativos (BERNARDES, 2003).

Sachs (2004) afirma que as causas dessa crise se devem à concepção de que desenvolvimento é sinônimo de crescimento econômico, o qual tem promovido a escassez de bens e ativos ambientais, beneficiando apenas alguns, ao mesmo tempo em que o Estado é incapaz de prover as necessidades básicas de toda população (moradia, saneamento, transporte, segurança etc.), gerando uma sociedade de injustiça social e ambientalmente insustentável.

A discussão sobre a relação entre educação e meio ambiente ganhou força dentro do próprio contexto de debate da crise ambiental e, em 1977, durante a Primeira Conferência Intergovernamental sobre Educação Ambiental (EA), em Tbilisi, teve elaborados objetivos, princípios, estratégias e recomendações (LIMA, 1999).

Após Tbilisi, foram estabelecidos critérios orientadores que propuseram que o desenvolvimento da EA deveria: privilegiar atividades contínuas; ter caráter interdisciplinar; associar os aspectos econômicos, político, cultural, social e ecológico da questão ambiental; ser voltada para a participação social e para a solução dos problemas ambientais; visar a mudança de valores, atitudes e comportamentos sociais (DIAS, 1993).

A EA é uma importante ferramenta de intervenção e transformação social, não só para aumentar o conhecimento acerca do tema, mas para incentivar a aquisição de habilidades e valores que orientem e motivem um estilo de vida sustentável (SILVA, 2008).

Realmente, a cada dia a crise ambiental nos desafia a promover mudanças em nosso modelo civilizatório, sob pena de não sobrevivermos aos problemas que temos causado. Essas mudanças são notáveis nas diversas esferas do sistema social: a comunicação agora dispensa grande atenção às questões ambientais; a tecnologia busca a ecoeficiência; a política incorporou a causa ambiental em programas de governo, implementou legislação específica e viu surgir um partido verde; o adjetivo ambiental foi assimilado por várias áreas, tais como o direito e a economia, além da educação (LAYRARGUES, 2009).

Atentando para a legislação que regulamenta a questão ambiental, queremos destacar: a Constituição Federal de 1988, que determina o meio ambiente ecologicamente equilibrado como direito de todos, impondo ao Poder Público e à coletividade a sua defesa e preservação (BRASIL, 1988); a Política Nacional do Meio Ambiente, Lei 6.938 de 1981 (BRASIL, 1981); e a Política Nacional de Educação Ambiental, Lei 9.795, de 1999 (BRASIL, 2002).

O Exército Brasileiro (EB), instituição nacional permanente, também participou deste importante cenário de mudanças, e, em conformidade com a legislação federal vigente, aprovou várias normalizações internas referentes às questões ambientais (BASTOS, 2007).

Neves e Rozemberg (2010) realizaram um estudo sobre as normas e legislações internas do EB relacionadas ao tema ambiental, apresentando os vários decretos e portarias em ordem cronológica, e comparando a implementação do Sistema de Gestão Ambiental do Exército Brasileiro às normas internacionais de qualidade relativas à gestão ambiental (NEVES; ROZEMBERG, 2010). Os autores concluíram que a estrutura do EB traz elementos que 
podem favorecer a operação do sistema da gestão ambiental, tais como: a prática da inspeção regular das chefias militares nas suas organizações subordinadas, que pode servir para a futura capacitação para as auditorias recomendadas pela Norma; a formação, treinamento e experiência para realizar registros militares, que pode ser aplicada ao registro de tarefas que tenham o potencial de causar impacto(s) ambiental(is) significativo(s) identificado(s) pela organização; e as atividades de rotina das organizações militares que preconizam cuidados para não deixar vestígios no ambiente, que favorecem, por exemplo, o cumprimento dos planos de gestão ambiental no tocante ao destino de resíduos.

A prática da EA na Instituição tem sua importância reconhecida por diversos autores, por motivos variados, que vão além do simples cumprimento da legislação, por exemplo, pelo seu poder de alcance extraordinário, seja devido ao número significativo de pessoas (acesso de novos oficiais, soldados e alunos a cada ano), à diversidade de público (militares de diferentes categorias, servidores civis de diversas áreas, estudantes dos colégios militares, público externo etc.) ou à distribuição geográfica por todo o país (BARCELLOS 2006, BASTOS 2007; OLIVEIRA 2009; NEVES; ROZEMBERG, 2010).

Deve-se considerar também que é crescente o envolvimento do EB em atividades ambientais por meio de ações subsidiárias de cunho educativo, caracterizando uma EA informal (COSTA, 2008). Portanto, é de grande interesse saber se a EA está sendo efetivamente implementada no EB, e qual orientação político-pedagógica vem regendo suas práticas, dado que existem, pelo menos, dois grandes blocos político-pedagógicos que possuem interfaces e vertentes internas diferenciadas: um denominado conservador ou comportamentalista, e outro chamado de transformador, crítico ou emancipatório (LOUREIRO, 2005).

Embora a vertente dominante seja a conservacionista, queremos destacar a corrente transformadora, crítica e emancipatória, que se caracteriza por dar ênfase à educação como processo permanente, cotidiano e coletivo, pelo qual agimos e refletimos transformando a realidade. A EA transformadora foca pedagogias problematizadoras para buscar caminhos democráticos, sustentáveis e justos para todos, baseando-se na crítica e autocrítica, e na ação política para estabelecer movimentos emancipatórios e de transformação social (LOUREIRO, 2004).

A prática da EA está ligada à questão ambiental, e é senso comum que deve promover mudanças, contudo, há dificuldade em vincular questões ambientais e sociais, que são indissociáveis. Fazer uma EA com responsabilidade social implica considerar os contextos socioeconômicos, político e cultural, não deixando de desenvolver uma consciência ecológica, mas contextualizando seu projeto político-pedagógico para enfrentar, além da degradação ambiental, também a padronização cultural, exclusão social, concentração de renda e apatia política (LAYRARGUES, 2009).

Ao falarmos em construção do ato pedagógico, trata-se do processo que vai do planejamento à realização. É o chamado processo, ato ou ação pedagógica, ou, ainda, prática educativa. É onde se concretizam os pressupostos da proposta de educação, ou seja, é colocar o discurso na prática. Ele tem variações dependendo de condições como: infraestrutura, recursos financeiros, disponibilidade de tempo, demanda do grupo etc. Pode ser um curso, oficina, seminário, pesquisa-ação, ciclo de debates, diagnóstico rápido participativo ou qualquer outro tipo de arranjo pedagógico (QUINTAS, 2009).

Dada a variedade de práticas pedagógicas possíveis, e o papel importante do EB, que contribui tanto na garantia do meio ambiente ecologicamente equilibrado quanto na promo- 
Neves, E. B.

ção da EA, em cumprimento à legislação vigente, o presente trabalho buscou diagnosticar como a EA vem sendo desenvolvida no Exército Brasileiro.

\section{Metodologia}

Este estudo utilizou-se da abordagem qualitativa, pois trabalhou com um universo de informações sobre valores, motivos e atitudes que não são facilmente traduzidos por operações entre variáveis (MINAYO, 2000), e possui particularidades que, conforme Godoy (1995, p. 58), caracterizam esse tipo de estudo, dentre elas: "considera o ambiente como fonte direta dos dados cuja análise é realizada de forma intuitiva e indutivamente pelo pesquisador, considerado como instrumento chave, e não requer o uso de técnicas e métodos estatísticos".

Apresenta, ainda, um enfoque descritivo, através do procedimento técnico de levantamento, no qual se interrogam diretamente as pessoas cujo comportamento se quer conhecer (GIL, 1991), neste caso com o método survey, onde se obtêm informações de um grupo, que é representante de uma população (PINSONNEAULT; KRAEMER, 1993). Para obter essas informações, utilizou-se, como ferramenta de coleta de dados, um questionário com perguntas abertas.

Neste sentido, foram selecionadas 52 unidades, de forma não probabilística e por conveniência, a saber: quarenta Organizações Militares Operacionais ou de Saúde que fazem parte do Comando Militar do Leste, um dos Comandos Militares de Área do Exército, e que abrange os estados do Rio de Janeiro, Minas Gerais e Espírito Santo; e 12 Colégios Militares distribuídos pelas cinco regiões geográficas do Brasil.

O questionário foi enviado a essas organizações militares, no mês de agosto de 2009, com um prazo de sessenta dias para ser respondido, através de ofício. O questionário foi composto da seguinte forma: em sua primeira parte, uma apresentação onde se esclarece o objetivo do estudo; e, numa segunda parte, duas perguntas abertas (a primeira foi elaborada com o intuito de identificar quais tipos de ações de incentivo à preservação e conservação do meio ambiente têm sido desenvolvidas no âmbito da unidade, e a segunda pergunta, de modo semelhante, refere-se à existência e descrição de possíveis práticas de EA).

A análise dos dados deu-se através da análise de conteúdo, método que consiste em adotar procedimentos sistemáticos e objetivos de descrição do conteúdo das respostas, visando obter indicadores que permitam inferir conhecimento acerca da produção dessas informações. Segundo Laville e Dionne (1999), a análise de conteúdo é, sobretudo, aplicada nos dados que se apresentam como texto, e consta de três etapas para o processo: a etapa do recorte dos conteúdos; a definição das categorias analíticas; e a categorização final das unidades de análise.

O recorte de conteúdos: durante a leitura dos textos foram recortados trechos que pudessem representar o significado profundo das ideias contidas no todo. Os elementos assim recortados constituíram as unidades de registro. Segundo Laville e Dionne (1999), essas unidades consistem em fragmentos do discurso manifesto como palavras, expressões, frases ou, ainda, ideias referentes a temas recortados.

A definição das categorias analíticas: é a fase que demanda mais tempo, pois se faz a identificação de caracteres comuns e consequente agrupamento. Neste passo, subdividimos as Organizações Militares em três conjuntos: as de saúde (hospitais, clínicas e afins); as de Ensi- 
no Fundamental (os Colégios Militares) e as operacionais (quartéis propriamente ditos, que executam atividades tais como instrução e adestramento de pessoal), por apresentarem atividades bem distintas e, com isso, a possibilidade de atitudes e motivações diferenciadas em relação ao meio ambiente e à $\mathrm{EA}$, embora ambos estejam estreitamente ligados às questões ambientais.

A categorização final das unidades de análise: a categorização final foi realizada por meio da alocação dos conteúdos às categorias estabelecidas a partir de um processo iterativo característico do modelo circular da pesquisa qualitativa. O processo permite uma análise mais profunda dos recortes com base em critérios discutidos e incorporados. Trata-se de considerar uma a uma as unidades à luz dos critérios gerais de análise, para escolher a categoria que convém melhor a cada uma (LAVILLE; DIONNE, 1999).

Esta pesquisa seguiu todas as orientações presentes na Resolução n 196/96 (BRASIL, 1996) do Conselho Nacional de Saúde no que diz respeito à pesquisa envolvendo seres humanos. Seu protocolo de pesquisa foi aprovado pelo Comitê de Ética da Escola Nacional de Saúde Pública (RJ) sob o n¹97/09. Para manter o anonimato das OM analisadas, designou-se a cada uma um código composto pela sigla "OM" acrescida de um numeral (Ex. OM1, $\mathrm{OM} 2$, e assim por diante).

\section{Resultados}

Decorrido o prazo de 60 dias após o envio dos questionários, obtivemos resposta de $24 \mathrm{OM}$ das 52 selecionadas, representando um percentual de 46,15\% da amostra inicial pretendida. Muitos motivos podem ter contribuído para a não-obtenção de resposta por parte de todas as unidades, dentre eles pode-se destacar o fato de o questionário estar ligado à uma pesquisa científica acadêmica desenvolvida por terceiros, e não a uma avaliação institucional.

Os 24 questionários respondidos foram divididos em três conjuntos conforme os tipos de OM, que ficaram assim representados: Organizações Militares Operacionais: 13 (54,17\% do total de questionários respondidos); Organizações Militares de Saúde: sete (29,16\% do total de questionários respondidos); e Colégios Militares: quatro (16,67\% do total de questionários respondidos).

\section{Organizações Militares Operacionais}

Das 13 OM operacionais que nos responderam, duas admitiram não executar quaisquer ações de incentivo à prevenção, preservação, conservação, melhoria ou recuperação do meio ambiente. Dentre as demais, o tipo de ação mais executada é a simples abordagem do assunto, citada por sete das onze unidades, o que representa pouco mais de $63 \%$, e frequentemente realizada por meio de palestras.

Outras ações descritas foram: a preocupação com lixo, resíduos e reciclagem; com a utilização de recursos naturais como água, energia e papel; a proteção de áreas verdes e plantio de mudas; existência de uma equipe de combate a incêndios preparada para ocorrências florestais; e cumprimento da legislação vigente. Além disso, a OM16 citou a criação de um espaço destinado ao público externo, como está descrito no trecho transcrito: "A OM implan- 
Neves, E. B.

tou, ainda, um Espaço Ecológico, com a finalidade de conscientizar os visitantes, principalmente crianças quanto à importância da preservação do meio ambiente".

Perguntados se têm promovido EA, oito OM responderam afirmativamente, representando $61,5 \%$ do total das unidades operacionais, enquanto cinco $(38,5 \%)$ deram resposta negativa.

Ao descrever no que consiste essa EA, a maioria das unidades que a promovem (cinco dentre oito, ou seja, 62,5\%) relatou a abordagem do assunto, sendo duas especificamente através de palestras. Outras práticas mencionadas foram: a seleção do lixo, instruções de combate a incêndios eficaz em ocorrências florestais, plantio de mudas, proteção da Área de Preservação Permanente (APA) existente nos domínios da unidade, e o estudo da inserção da EA como matéria dentro das instruções militares.

Apenas a OM16 desenvolve um Projeto, descrito na transcrição:

A OM possui um projeto com crianças de uma comunidade carente da cidade, são realizadas palestras, atividades de orientação (Projeto Orientar para Preservar) e caminhadas ecológicas na área do campo de instrução, com o intuito de mostrar a necessidade de proteção do meio ambiente.

Cabe ressaltar que sete das oito OM promotoras de EA fizeram uso, direto ou indireto, da palavra preservação, como podemos observar nas transcrições abaixo:

A educação ambiental promovida pelas OM consiste, basicamente, na exploração do assunto, em enfatizarmos a importância de preservarmos o meio ambiente, e, tornar um dever de cada um colaborar para a preservação/ renovação dos elementos naturais (citação direta do termo preservação pela OM1).

Educação ambiental é o processo que consiste em conscientizar todos os militares da importância do tema em questão. Seria mostrar como devemos conservar nossas áreas ambientais, nossas vegetações, árvores, matos. Prover a limpeza e mantê-la em boas condições (citação indireta do termo pela OM18, transmitindo a ideia de preservação).

Essa alta incidência do termo pode indicar uma grande preocupação com o aspecto ecológico da degradação ambiental em detrimento dos demais (econômico, político etc.), que não tiveram nenhuma citação direta ou indireta.

\section{Organizações Militares de Saúde}

Quando questionados sobre quais ações de incentivo à prevenção, preservação, conservação, melhoria e recuperação do meio ambiente foram realizadas no âmbito da unidade, uma OM respondeu que nenhuma ação foi realizada. 
As outras seis descreveram suas ações, dentre as quais as mais citadas foram: o tratamento dos resíduos/lixo (quatro citações) e a simples abordagem do assunto através de palestras ou tópicos de reuniões (três citações). Outras ações mencionadas foram a preocupação com o consumo de recursos como água e energia, e, também, em não permitir derrubadas de árvores. Apenas a OM4 afirmou que desenvolve ações do tipo programa, o Programa D’Olho na Qualidade, e o RECICLOEX, descrito, a seguir, na transcrição de parte da resposta: "Programa RECICLOEX (conscientização, reconhecimento dos recicláveis, dos resíduos de saúde e químicos)".

É perceptível a preocupação com o destino dos resíduos nas respostas, o que pode ser explicado por tratar-se de resíduos de serviços de saúde, que, por força de lei, devem ter uma destinação adequada. Outro ponto notável é que a maioria das ações descritas é de caráter pontual. Apenas uma é do tipo programa, ou seja, de caráter contínuo.

Com relação à existência e descrição das práticas de EA, diferentemente da primeira pergunta onde apenas uma organização deu resposta negativa, a maior parte admitiu não promover a EA de nenhuma forma. Foram quatro as unidades com esse tipo de resposta, representando $57 \%$ das OM de saúde. Dentre as três que responderam de forma positiva, duas citaram a palavra preservação ao descrever suas práticas, como, por exemplo, no trecho transcrito: "A Educação Ambiental é promovida através de palestras sobre preservação e importância do meio ambiente".

Como práticas de EA, a mais citada foi o cumprimento da legislação vigente, como se observa no trecho transcrito: "Quando há a preocupação em cumprir as normas aplicadas pelas sucursais da Vigilância Sanitária, estamos promovendo através destas ações descritas uma forma aplicada de Educação Ambiental de nossos profissionais técnicos”, citado pela OM7. As demais foram atividades como promover palestra, coleta seletiva, reciclagem, gerenciamento de resíduos e plantio de árvores.

\section{Colégios Militares}

Embora uma amostra pequena normalmente possua menor probabilidade de ser representativa em relação à população, de acordo com Bandeira (2009), quando o fenômeno é menos variável, ela pode ser representativa da população, o que pode ser observado nesse estudo, pois, todos os Colégios Militares (CM) são regidos segundo um mesmo conjunto de normas e regulamentos, dentre os quais podemos citar as Normas de Planejamento e Gestão Escolar - NPGE (BRASIL, 2009) e o Regulamento dos Colégios Militares - R-69. (BRASIL, 2008).

Assim, acredita-se que os dados alcançaram o ponto de redundância, o que significa que, embora a amostra utilizada no trabalho represente apenas 33\% da amostra inicial, muito provavelmente não apareceriam novas categorias de atividades mesmo que 100\% dos questionários tivessem sido respondidos (LINCOLN; GUBA, 1985).

A omissão por parte de $66 \%$ dos CM entrevistados pode ser explicada pela falta de relevância dada à EA nestes estabelecimentos de ensino, ou, ainda, por receio de uma exposição do CM. A mesma análise pode ser aplicada às categorias anteriores. 
Neves, E. B.

Todos os CM responderam de forma positiva quanto à promoção da $\mathrm{EA}$, como pode ser percebido nos trechos a seguir: "Sim, nós promovemos a educação ambiental através de ações e informações que estejam dentro de um processo dinâmico/interativo, que possam transformar posturas individuais, que sejam participativas, abrangentes envolvendo a familia e a coletividade" (OM21) e "Sim, o CM trabalha efetivamente a Educação Ambiental, seja ela dentro de sala de aula nas diversas disciplinas, seja nas atividades extracurriculares, desenvolvendo, desta forma, a interdisciplinaridade proposta pelo tema" (OM23).

Tal fato é extremamente importante uma vez que a escola tem papéis cruciais em sistematizar e socializar o conhecimento, além de atuar na formação de cidadãos informados, conscientes e atuantes que possam não só discutir como, também, buscar soluções para as questões ambientais (LUCATTO; TALAMONI, 2007).

As ações e atividades desenvolvidas pelos CM, citadas nos questionários, foram: "Exibição de filmes sobre a temática ambiental"; "Palestras"; "Projetos interdisciplinares: Lixo, Aquecimento Global etc."; e "Oficinas de reutilização e reciclagem de resíduos".

Em relação aos profissionais responsáveis pelas atividades de EA, dois CM relataram que os profissionais responsáveis são os professores das áreas das ciências, entretanto, ambos mencionaram que os mesmos estão subordinados a um "oficial de meio ambiente" ou de “gestão ambiental". Já a OM22 afirmou que "o gerente da equipe de gestão ambiental é um professor com mestrado em Ecologia", enquanto a OM21 disse apenas ser "o professor de cada série". Esses resultados demonstram uma tendência à concentração das atividades de EA entre os professores de áreas mais afins, como ciências e biologia.

Dos quatro CM, três incluíram, em suas ações, atividades de cunho interdisciplinar, estando de acordo com os PCNs que afirmam que "a riqueza do trabalho será maior se os professores de todas as disciplinas discutirem e, apesar de todo o tipo de dificuldades, encontrarem elos para desenvolver um trabalho conjunto" (BRASIL, 1998), embora não tenham descrito em detalhes como estas atividades são desenvolvidas, tendo apenas citado tais atitudes. A OM21, por exemplo, apenas menciona a realização de "testes sobre problemas ambientais", já a OM22 cita o desenvolvimento de "Projetos interdisciplinares: Lixo, Aquecimento Global etc."

\section{Discussão}

Se, por um lado, observou-se que várias OM citaram o cumprimento da legislação, mostrando preocupação com o tema no âmbito da unidade, por outro lado, foi surpreendente constatar que três OM não executam quaisquer ações de prevenção, preservação, conservação, melhoria e recuperação do meio ambiente, uma vez que isso está previsto na Portaria 570, de 2001, do Comandante do Exército, que visa à implantação de ações de gestão ambiental no âmbito do Exército (BRASIL, 2001). Tais unidades também admitiram não promover a EA.

Notou-se que há uma identificação do cumprimento da legislação como prática de EA, geralmente pela ideia de que a capacitação para o cumprimento das normas transmite um conhecimento considerado como EA; no entanto, se não for trabalhado além do simples cumprimento de normas técnicas, poderá se tornar mecânico e desprovido de sentido cognitivo. Outras ações sofrem de problemas semelhantes, como a implementação de coleta seletiva 
Práticas de educação ambiental ...

e reciclagem, que, frequentemente, é tomada como prática de EA, e realmente o é, desde que trabalhada de forma contextualizada, do contrário desenvolve consciência ecológica sem compromisso social (LAYRARGUES, 2009).

\section{Atividades pontuais versus atividades contínuas}

Notadamente, a maior parte das ações descritas nas respostas analisadas foi de caráter pontual; atividades como o plantio de mudas, por exemplo, são frequentemente citadas como práticas de $\mathrm{EA}$, mas, geralmente, não passam de ações que carecem de uma conexão com a problemática ambiental em seus vários aspectos (histórico, econômico, cultural etc.). Atividades são chamadas de pontuais quando se referem às ações fragmentadas e esporádicas, frequentemente descontextualizadas, de caráter imediatista e, até mesmo, improvisado, que, por isso, tendem a surtir pouco ou nenhum efeito (JACOBI, 2004; GUERRA, 2004; MACHADO, 2008).

Tais ações são, muitas vezes, executadas com o único intuito de mostrar que algo está sendo feito, sem efetivamente desenvolver uma EA (MACHADO, 2008), contudo, podem se tornar atividades muito enriquecedoras se inseridas dentro de um projeto político-pedagógico que faça sua devida contextualização, necessária em toda prática educativa, pois o mero status de programa não confere, a uma atividade, o caráter contextualizado.

Todas as Organizações Militares que relataram alguma ação na questão ambiental citaram, dentre as atividades listadas, alguma de caráter pontual, como filmes, palestras e Semana do Meio Ambiente, o que implica o desenvolvimento de uma EA reducionista e fragmentada. As chamadas atividades pontuais são ações fragmentadas e isoladas que passam a noção de que algo está sendo feito, ao mesmo tempo em que impedem que a EA seja efetivamente incluída no currículo escolar (MACHADO, 2008).

Tais atividades estão inseridas em uma EA conservadora, que possui uma compreensão naturalista e conservacionista da crise ambiental, cujos ensinamentos conduzem apenas ao uso racional dos recursos naturais, sem se preocupar com uma problematização da realidade e com o meio ambiente humano (LOUREIRO, 2005), pouco contribuindo para uma prática educativa que venha a ser transformadora, crítica e emancipatória.

Assim, para que a EA seja desenvolvida tendo como foco a mudança de comportamento, encontrando, na escola, um agente transformador da cultura e da sensibilização das pessoas para os problemas ambientais, se faz necessário pensá-la associada a: ética, política, ciência, cultura, tecnologia e, também, ecologia (TRAVASSOS, 2001).

Nas respostas relacionadas à promoção da EA, foi significativo o número de OM que descreveram suas práticas citando, direta ou indiretamente, a palavra preservação, com alusão ao aspecto ecológico da problemática ambiental; ao passo que não foram observados quaisquer termos que fizessem referência, direta ou indireta, aos demais aspectos (histórico, político, econômico etc.), o que caracteriza um enfoque conservacionista.

A própria normalização interna do Exército demonstra a necessidade de que a EA seja desenvolvida de forma contextualizada e transdisciplinar, o que pode ser observado na portaria $\mathrm{n}^{\circ} 14$ do Departamento de Ensino e Pesquisa de 2008 (Brasil, 2008), que aprovou as normas para a promoção da EA nos estabelecimentos de ensino; todavia este foi o primeiro documento do Exército Brasileiro específico para a EA, pois, até então, a mesma era apenas 
Neves, E. B.

citada de forma vaga dentro de outros documentos relacionados à questão ambiental (BRASIL, 2008).

Sabemos, no entanto, que embora a EA venha conquistando espaço na agenda das instituições, o seu financiamento, enquanto política pública, ainda é precário, sendo assim, o acesso aos recursos públicos não acompanhou o avanço e amadurecimento das práticas pedagógicas, o que pode representar um empecilho para sua realização (SOTERO, 2008).

Travassos (2001) alega que muitos educadores, preocupados com os problemas ambientais, acreditam que a EA deve se voltar para o desenvolvimento de uma consciência conservacionista, relacionada com aspectos naturalistas, e a partir dessa visão surge a maioria das ações educacionais direcionadas predominantemente para a defesa do meio natural.

Tanto a corrente conservacionista quanto a da ecoeficiência (que acredita na eficiência técnica para superar a crise) são correntes legitimadas pela ideologia dominante, pois funcionam segundo a lógica do mercado, ou sem questioná-la, não se preocupando em mudar a estrutura do sistema político-econômico hegemônico. Por isso são bem aceitas pela opinião pública e largamente difundidas pelos meios de comunicação de massa, e, com o passar do tempo, essas correntes têm se tornado complementares (LOUREIRO; BARBOSA; ZBOROWSKI, 2009).

Em contrapartida, atividades contínuas, permanentes ou continuadas fazem referência às ações, tais como programas, ou outras atividades, que aconteçam de forma cotidiana e articulada com a realidade, possibilitando resultados mais duradouros (FERRARO, 2004; SILVA, 2008).

Alguns CM relataram desenvolver ações interdisciplinares e de caráter contínuo e permanente, sendo executadas ao longo de todo ano letivo, envolvendo não só o público interno, mas, também, a família e comunidade. Dentre estas atividades, destacaram-se as Oficinas de Reciclagem, a Coleta Seletiva Solidária e o Projeto Horta, além dos chamados projetos interdisciplinares.

A interdisciplinaridade consiste na combinação de várias áreas do conhecimento e mostra que é necessário o desenvolvimento de metodologias interativas com a abrangência de enfoques e tornando possível uma nova articulação das relações entre as ciências naturais, sociais e exatas (JACOBI, 2005); assim, ações interdisciplinares contribuem para a ampliação dos conhecimentos de todos os envolvidos, além de auxiliarem na formação de cidadãos mais conscientes e críticos da sua realidade (LUCATTO; TALAMONI, 2007).

A importância de atividades interdisciplinares se mostra ainda maior quando se constata que os problemas que afetam a vida do nosso planeta são de natureza global, e que a compreensão de suas causas não pode ficar restrita somente aos fatores estritamente biológicos, revelando dimensões políticas, econômicas, institucionais, sociais e culturais JACOBI, 2005); todavia, essa visão interdisciplinar depende de um trabalho de capacitação e treinamento dos professores, pois, trata-se de trabalhar com várias áreas do conhecimento ao mesmo tempo (TRAVASSOS, 2001), uma vez que, de acordo com Jacobi et al. (2009), as práticas educativas interdisciplinares ainda são recentes e incipientes e têm como maior desafio superar a compartimentalização científica provocada pela excessiva especialização.

Além dos fatores supracitados, outro aspecto importante a ser ressaltado é o envolvimento da família no cotidiano das atividades escolares. De acordo com De Carvalho (2000), o 
Práticas de educação ambiental ...

apoio sistemático da família, compensando tanto dificuldades individuais quanto deficiências escolares, contribui, de forma significativa, para o sucesso escolar do indivíduo.

\section{Conclusão}

Apesar da preocupação observada em várias OM, no que se refere ao cumprimento da legislação vigente quanto aos aspectos ambientais, constatamos que algumas unidades não têm cumprido a normalização interna que determina o incentivo às ações de gestão ambiental descritas na Portaria 570, de 2001 do Comandante do Exército (BRASIL, 2001).

Nas OM que executam as referidas ações, as atividades mais mencionadas foram: a abordagem do assunto por meio de palestras, instruções ou reuniões; a preocupação com o lixo, rejeitos, reciclagem e uso dos recursos naturais; o plantio de mudas, proteção de áreas verdes e instrução de combate a incêndios.

Constatou-se a citação, direta ou indireta, da palavra preservação em $81 \%$ das respostas que descrevem a EA praticada nas $\mathrm{OM}$, que faz referência ao aspecto ecológico da questão ambiental em detrimento dos demais aspectos (histórico, político, econômico etc.), para os quais não foram identificados, no conteúdo das respostas, quaisquer termos relacionados, o que caracteriza uma EA de enfoque conservacionista. Nos Colégios Militares, pela própria natureza e finalidade da Organização Militar, constatou-se um avanço maior no sentido do desenvolvimento de uma EA privilegiando as ações contínuas e contextualizadas, favorecidas pelo aspecto da interdisciplinaridade do tema.

Por fim, sugere-se que os militares do Exército Brasileiro somem esforços com o objetivo de alcançar um processo educativo problematizador e comprometido com transformações de cunho emancipatório, isto é, uma EA crítica, transformadora e emancipatória.

\section{Referências}

BANDEIRA M. Planificação Operacional na Pesquisa. Disponível em: http:// www.ufsj.edu.br/portal-repositorio/File/lapsam/Texto $\% 208$-PLANIFICACAO $\% 20$ OPERACIONAL\%20DA\%20PESQUISA.pdf . Acesso em: 06 de novembro de 2009.

BARCELLOS, Z. R. A questão ambiental da Amazônia: uma abordagem pré-conflito na estratégia da resistência. 2006. 87 f. Trabalho de conclusão de curso (Política, Estratégia e Alta Administração do Exército)-Escola de Comando e Estado-Maior do Exército, Rio de Janeiro, 2006.

BASTOS, K. S. O. Política ambiental do Exército Brasileiro - uma proposta. 2007. 48

f. (Trabalho de Conclusão de Curso) - Escola de Comando e Estado-Maior do Exército, Rio de Janeiro, 2007. 
Neves, E. B.

BERNARDES, J. A.; FERREIRA, F. P. M. Sociedade e natureza. In: CUNHA, S. B.; GUERRA, A. T. (Org.). A questão ambiental: diferentes abordagens. Rio de Janeiro: Bertrand Brasil, 2003. p. 17-41.

BRASIL. Conselho Nacional de Saúde. Resolução 196/96. Diretrizes e Normas Regulamentadoras de Pesquisas Envolvendo Seres Humanos. Disponível em: <http:// www.univap.br/cep/res19696.pdf>. Acesso em: 05 abr. 2009.

Constituição (1988). Constituição da República Federativa do Brasil: promulgada em 5 de outubro de 1988: atualizada até a Emenda Constitucional nº. 57, de 18-12-2008. Diário Oficial da União, Brasília, 18 dez. 2008. Disponível em: <https:// www.planalto.gov.br/ccivil_03/Constituicao/Constitui\%C3\%A7ao.htm>. Acesso em: 14 abr. 2009.

Decreto $\mathrm{N}^{\circ}$ 4.281, de 25 de junho de 2002. Regulamenta a Lei $\mathrm{N}^{\circ}$ 9.795, de 27 de abril de 1999, que institui a Política Nacional de Educação Ambiental, e dá outras providências. Diário Oficial da União, Brasília, 26 jun. 2002. Disponível em: $<$ http:// www.planalto.gov.br/ccivil_03/decreto/2002/d4281.htm>. Acesso em: 5 abr. 2009.

Exército Brasileiro. Portaria no 014-DEP, de 8 de fevereiro de 2008. Aprova as Normas para a promoção da educação ambiental nos estabelecimentos de ensino e nas organizações militares subordinados e/ou vinculados ao departamento de ensino e pesquisa. Boletim do Exército, Brasília, n. 8, p. 20-33, 22 fev. 2008. Disponível em: <http://www.sgex.eb.mil.br/sistemas/be/indices_arq.php>. Acesso em: 11 maio 2009.

Lei $n^{\circ}$. 6.938, de 31 de agosto de 1981. Dispõe sobre a Política Nacional do Meio Ambiente, seus fins e mecanismos de formulação e aplicação, e dá outras providências. Diário Oficial da União, Brasília, 02 set. 1981. Disponível em: < http://www.mma.gov.br/ port $/$ conama/legiano1.cfm?codlegitipo=1\&ano=1981>. Acesso em: 5 abr. 2009.

Ministério da Defesa. Exército Brasileiro. Portaria no 570, de 6 de novembro de 2001. Aprova a Política de Gestão Ambiental do Exército Brasileiro. Boletim do Exército, Brasília, n. 46, p. 27-28, 16 nov. 2001. Disponível em: <http://www.sgex.eb.mil.br/ sistemas/be/boletins.php>. Acesso em: 11 maio 2009.

. Ministério da Defesa. Normas de planejamento e gestão escolar. Brasília, 2009.

Parâmetros Curriculares Nacionais. Secretaria de Educação Fundamental. Brasília: MEC / SEF, 1998.

COSTA, R. G. A. Educação ambiental institucionalizada no Exército Brasileiro: (de)limitações epistemológicas das práticas em curso. Revista Eletrônica do Mestrado em Educação Ambiental, Rio Grande, v. 20, n. 1, p. 171-179, 2008.

DE CARVALHO, M. E. P. Relações entre família e escola e suas implicações de gênero. Cadernos de Pesquisa, n. 110, p. 143-155, 2000.

DIAS, G. F. Educação ambiental, princípios e práticas. São Paulo: Gaia, 1993.

FERRARO, L. A. J. Um olhar sobre a Rupea - uma rede também deve ser um guardachuva? Revista Brasileira de Educação Ambiental, Brasília, v. 0, p. 126-132, 2004. 
Práticas de educação ambiental ...

GIL, A. C. Como elaborar projetos de pesquisa. 3. ed., São Paulo: Atlas, 1991.

GODOY, A. S. Introdução à pesquisa qualitativa e suas possibilidades. Revista de Administração de Empresas, São Paulo, v. 35, n. 2, p. 57-63, 1995.

GUERRA, A. F. S. Tecendo a rede de educadores ambientais da região sul - REASul. Revista Brasileira de Educação Ambiental, Brasília, v. 0, p. 99-107, 2004.

JACOBI, P. R. Educação ambiental: o desafio da construção de um pensamento crítico, complexo e reflexivo. Educação e pesquisa, v. 31, n. 2, p. 233-250, 2005.

Educação e meio ambiente - transformando as práticas. Revista Brasileira de Educação Ambiental, Brasília, v. 0, p. 28-35, 2004.

JACOBI, P. R.; TRISTÃO, M.; FRANCO, M. A função social da educação ambiental nas práticas colaborativas: participação e engajamento. Cadernos Cedes, v. 29, n. 77, p. 63-79, 2009.

LAVILLE, C.; DIONNE, J. A construção do saber. Belo Horizonte: Editora UFMG, 1999.

LAYRARGUES, P. P. Educação ambiental com compromisso social: o desafio da superação das desigualdades. In: LOUREIRO, C. F. B.; LAYRARGUES, P. P.; CASTRO, R. S. (Org.).

Repensar a educação ambiental um olhar crítico. São Paulo: Cortez, 2009. p. 11-31.

LIMA, G. C. Questão ambiental e educação: contribuições para o debate. Ambiente \& Sociedade, Campinas, v. 2, n. 5, p. 135-153, 1999.

LINCOLN, Y. S.; GUBA, E.G. Naturalistic inquiry. Beverly Hills: Sage, 1985.

LOUREIRO, C. F. B. Educação ambiental transformadora. In: LAYRARGUES, P. P. (Org.). Identidades da educação ambiental brasileira. Brasília: Ministério do Meio Ambiente, 2004. p. 65-84.

Complexidade e dialética: contribuições à práxis política e emancipatória em educação ambiental. Educação e Sociedade, Campinas, v. 26, n. 93, p. 1473-1494, 2005.

LOUREIRO, C. F. B.; BARBOSA, G. L; ZBOROWSKI, M. B. Os vários "ecologismos dos pobres" e as relações de dominação no campo ambiental. In: LOUREIRO, C. F. B.; LAYRARGUES, P. P.; CASTRO, R. S. (Org.). Repensar a educação ambiental um olhar crítico. São Paulo: Cortez, 2009. p. 81-118.

LUCATTO, L. G.; TALAMONI, J. L. B. A construção coletiva interdisciplinar em educação ambiental no ensino médio: a microbacia hidrográfica do Ribeirão dos Peixes como tema gerador. Ciência \& Educação, Bauru, v. 13, n. 3, p. 389-398, 2007.

MACHADO, J. T. Um estudo diagnóstico da educação ambiental nas escolas do ensino fundamental do município de Piracicaba/SP. In: ENCONTRO NACIONAL DA ANPPAS, 4., Brasília. Anais... Brasília, 2008. Disponível em: <http://www.anppas.org.br/encontro4/ cd/ARQUIVOS/GT9-274-130-20080509104139.pdf>. Acesso em: 08 nov. 2009.

MINAYO, M. C. S. O desafio do conhecimento: pesquisa qualitativa em saúde. 7. ed. São Paulo: Hucitec, 2000. 
Neves, E. B.

NEVES, E. B.; ROZEMBERG, B. Estudo comparativo entre o sistema de gestão ambiental do Exército Brasileiro e a Norma ISO 14001. Revista de Gestão Social e Ambiental, São Paulo, v. 4, n. 1, p. 159-177, 2010.

OLIVEIRA, J. O. Educação ambiental e operações militares: a legislação do Exército Brasileiro sobre educação ambiental. 2009. 33 f. Trabalho de Conclusão de Curso (Especialização)-Escola de Aperfeiçoamento de Oficiais, Rio de Janeiro, 2009.

PINSONNEAULT, A.; KRAEMER, K. L. Survey research methodology in management information systems: an assessment. Journal of Management Information Systems, Armonk, v. 10, n. 2, p. 75-79, 1993.

QUINTAS, J. S. Educação no processo de gestão ambiental pública: a construção do ato pedagógico. In: LOUREIRO, C. F. B.; LAYRARGUES, P. P.; CASTRO, R. S. (Org.).

Repensar a educação ambiental um olhar crítico. São Paulo: Cortez, 2009. p. 33-80.

SACHS, I. Desenvolvimento includente, sustentável, sustentado. Rio de Janeiro: Garamond, 2004.

SILVA, A. S. A prática pedagógica da educação ambiental: um estudo de caso sobre o Colégio Militar de Brasília. 2008. 112p. Dissertação (Mestrado em Desenvolvimento Sustentável) - Universidade de Brasília, Brasília, 2008.

SOTERO, J. P. O financiamento público da Política Nacional de Educação

Ambiental: do veto do artigo 18 às novas estratégias de financiamento. 2008. $236 \mathrm{f}$. Dissertação (Mestrado em Desenvolvimento Sustentável)-Centro de Desenvolvimento Sustentável, Universidade de Brasília, Brasília, 2008.

TRAVASSOS, E. G. A educação ambiental nos currículos: dificuldades e desafios. Revista de Biologia e Ciências da Terra, João Pessoa, v. 1, n. 2, p. 1-12, 2001.

Artigo recebido em 08/05/2011. Aceito em 11/11/2011. 